\title{
ENTRE “TOTALITARISMOS” Y “UTOPÍAS”. LECTURAS DEL PENSAMIENTO POLÍTICO DEL SIGLO XIX
}

\section{María Carla Galfione*}

\section{Resumen}

El debate entre los eclécticos y los saintsimonianos respecto del objeto y el sentido de la filosofía y su relación con la política, que se desarrolla luego de 1830, y en relación con las diversas visiones de la monarquía constitucional francesa, nos sirve aquí para regresar sobre los modos de concebir la filosofía política. En nuestro trabajo seguimos de cerca este debate, repasamos algunas lecturas contemporáneas del siglo XIX y nos detenemos en particular en el pensamiento de Pierre Leroux. El alcance y el sentido que adoptan con Leroux los conceptos de religión, política y democracia son condición de posibilidad para pensar en una filosofía política que, dando lugar a la religión, pueda revalorizar el vínculo entre libertad, acción política y democracia.

Palabras clave: filosofía política, saintsimonismo, liberalismo, democracia, religión.

\section{Abstract}

The debate between eclectics and saint-simoniens about the object and sense of philosophy and its relationship with politics which took place in France after 1830 , in connection with different interpretations on constitutional French monarchy, gives a good oportunity to discuss the ways of conceiving political philosophy. We follow closely that debate, revising some lectures of the $19^{\text {th }}$ Century and paying attention especially to Pierre Leroux's thought. The implications and the sense that the concepts of religion, politics and democracy adopt with Leroux are, in our judgement, a condition of possibility to think a political philosophy that, giving place to religion, could revalue the links between freedom, political action and democracy.

Keywords: political philosophy, saintsimonism, liberalism, democracy, religion.

* Docente de la Universidad Nacional de Córdoba. Profesora y licenciada en Filosofía por esa Universidad y doctora en Ciencias Sociales y Humanas por la Universidad Nacional de Quilmes. En su tesis doctoral, defendida recientemente, se ocupa del pensamiento político argentino del siglo XIX y su vinculación con diversas líneas del pensamiento francés. Dirección electrónica: carlagalfione@yahoo.com.ar 
Paul Bénichou, uno de los estudiosos más consagrados del pensamiento y la cultura francesa el siglo XIX, reconoce en las definiciones del grupo comúnmente denominado "saintsimoniano" algunos de los principales rasgos, anticipatorios por cierto, de lo que sería el totalitarismo del siglo $\mathrm{XX}^{1}$. Sin duda, no es osado, y mucho menos original, reconocer en el siglo XIX algunas de las ideas que pueden encontrarse luego constituyendo los ejes de referencia de lo que podría reconocerse como el pensamiento filosófico legitimador de los totalitarismos en el siglo pasado. Sin embargo, cualquier lectura de este tipo, además de arriesgarse en una anticipación de sentido que excede lo reclamado por el objeto, supone ciertas generalizaciones que desconocen la compleja trama de los debates y condiciones histórico-políticas e intelectuales en las cuales se definen las posiciones. En lo que sigue nos interesa revisar esta lectura de Bénichou, valiéndonos de algunas otras interpretaciones y, principalmente, intentando detenernos en una de las fuentes más destacadas de aquel "saintsimonismo", para reconocer allí rasgos que no sólo nos permiten distanciarnos de la lectura de Bénichou, sino que nos sugieren la posibilidad de una interpretación según la cual aquellas definiciones decimonónicas se convierten en modelos para un pensamiento contemporáneo atento a las posibilidades de referirse a la relación entre filosofía política y emancipación.

\section{El contexto. La política como ciencia social}

Siguiendo la distinción de André Jardin entre "liberalismo del siglo XVIII" y "liberalismo del siglo XIX"2, puede reconocerse en el pensamiento político francés de la primera mitad del siglo XIX, el predominio de un "liberalismo" que se desarrolla luego de 1793 y

${ }^{1}$ Nos atenemos fundamentalmente a los desarrollos de Paul Bénichou en Fil tiempo de los profetas, México, Fondo de Cultura Económica, 1984. Bajo el "saintsimonismo" Bénichou incluye un amplio conjunto de intelectuales franceses cuya particularidad habría sido la de ser discípulos de las ideas del Conde de SaintSimon. Luego de la muerte del maestro, en 1825, el grupo se disuelve, conformándose entonces numerosos grupos que llegan a disputar tanto en el ámbito de la filosofía cuanto en el de la política.

${ }^{2}$ Nos referimos a la distinción que ofrece André Jardin en Historia del liberalismo politico, México, Fondo de Cultura Económica, 1998. 
permanece vivo a lo largo de todo el siglo siguiente. Al referirse al "liberalismo del siglo XIX" Jardin alude a aquella corriente que, sin renunciar a la defensa de la libertad individual, estaba, sin embargo, dispuesta a declinarla en caso de ver peligrar el orden y a apoyar ciertos modelos de concentración del poder. ${ }^{3} \mathrm{Y}$ entre sus principales teóricos se destacan los llamados "eclécticos" o "doctrinarios", con nombres tales como Guizot, Royer-Collard, Cousin y Jouffroy.

El liberalismo se presenta como el movimiento que intenta redefinir la libertad después de la experiencia revolucionaria, advirtiendo que aquella libertad, que nacía del Contrato social, se había convertido en tiranía ${ }^{4}$. El máximo representante del doctrinarismo es, sin duda, François Guizot, quien, como muchos de sus contemporáneos, temeroso ante las posibilidades de la institución del dominio de la mayoría, opone a la "soberanía del pueblo" rousseauniana la "soberanía de la razón". El logro de la Revolución, la realización de la igualdad, aparece como un hecho insoslayable, pero, precisamente por ello, urge revisar, según Guizot, la base sobre la cual se legitima, reconociendo en ésta algo que es en todo contrario a la pretendida "razón soberana". Para Guizot, hubo en ese acontecimiento, un movimiento social que debe inscribirse en la marcha de la historia, puesta que ésta es definida por él como "lucha de clases". La "igualdad social" se impuso en 1789. Sin embargo, ante el logro de la "igualdad social" -que en este marco debe entenderse como ascenso de la burguesía- no debe reclamarse, como algunos pueden pretender, también la realización de la igualdad política. Encabezando el planteo "doctrinario", Guizot sostiene la necesidad de un "sistema representativo" en el que los representantes sean

3 Poniendo de manifiesto esta propensión a la declinación de la libertad individual, Jardin destaca, por ejemplo, el hecho de que la sociedad liberal que "floreció bajo la monarquía de julio no fue una sociedad igualitaria. Es cierto que los ciudadanos disfrutaban de los mismos derechos en su vida privada. Pero la participación en los asuntos públicos quedó reservada a las clases censatarias separadas de la masa por un criterio discutible". Véase Ibid., p. 461.

${ }^{4}$ Cabe aclarar que la posición doctrinaria no agota todo el liberalismo del siglo XIX, sino que convive con otras formulaciones entre las que se destaca la de Benjamin Constant. Sobre las diferencias del planteo de Constant respecto del de Guizot: véase Roldán, Dario, "Liberales y doctrinarios: acerca de la tradición liberal en Francia", Revista de Occidente, N²32, 2000. 
los más capaces, conformando así una elite que se desprende del seno de la burguesía y es constituida por expertos, capaces de hacer real el gobierno de la razón ${ }^{5}$.

En breve, esta posición habrá de traducirse en una racionalización del gobierno y una cientifización de la política, que aboga por el dominio de la razón en contra de las pasiones que habría defendido el siglo anterior. Ante el avance de las masas parece necesario pensar en un sistema de gobierno que pueda ponerle freno y elaborar, al mismo tiempo, una justificación teórica para dicho gobierno. Tal como lo considera Pierre Rosanvallon, lo que en Guizot aparece es una lenta redefinición de la relación entre lo social y lo político.

Parado en el suelo común del liberalismo del siglo XIX, esto es, el rechazo del contrato, y afirmando que el sistema político es la manifestación de una sociedad que lo preexiste y no el productor de lo social, Guizot defiende una posición que difícilmente puede concebirse como democrática. El gobierno es una manifestación de la sociedad. El poder es "la expresión visible, una suerte de resumen, de un poder global y difuso. Es la cabeza de una sociedad a la que está completamente incorporado"6. En este contexto, la unidad social se deriva de las "inteligencias" que ocupan el gobierno, lo cual, en la práctica, no significa sino que es expresión de los intereses de las clases medias.

Guizot se refiere a la "soberanía de la razón", de la "justicia” y del "derecho". Lo humano, signado por la variedad y la falibilidad, no es punto de apoyo seguro para el poder. La multiplicidad no es garantía, sino, al contrario, amenaza y por ello se recurre a una "razón soberana" que se constituye como el punto nodal de este "liberalismo del siglo XIX". Según Rosanvallon, esta posición "es liberal en tanto que denuncia todas las formas de despotismo y niega a cualquiera el derecho de llamarse verdaderamente soberano, pero no reconoce, por ello, nada en los derechos

${ }^{5}$ Rosanvallon destaca en esto el parecido con Tocqueville. Véase Rosanvallon, Pierre, Le moment Guizot, Paris, Gallimard, 1985, p. 54 (la traducción de los textos franceses citados en el presente artículo es nuestra).

${ }^{6}$ Rosanvallon, Pierre, Le moment Guizot, Paris, Gallimard, 1985, p. 49. 
intrínsecos del individuo"7, ni voluntad, ni libertad constituyen la base de la soberanía. La "razón soberana", por el contrario, se reproduce en la esfera humana a través del "sentido común", construido con el aporte de la religión, pero encuentra su órgano de expresión privilegiado en la "filosofía", detentada por unos pocos: los más "capaces". La "capacidad" cumple un rol medular en la medida en que permite combatir y hasta eliminar la anarquía. De ahí también la posibilidad ensayada por Rosanvallon de ver en Guizot "el 'momento reaccionario' del pensamiento liberal"8.

Pero surge con esto otro elemento más que, si seguimos la sugerencia de Rosanvallon, nos permite reconocer una novedad. La teoría política se asienta sobre una sociología. Ya no se parte, como en el contractualismo, del hombre singular, sino de la estructura social. La política sujeta a la "capacidad" es la afirmación del dominio de la ciencia social. Y he ahí otro de los componentes de esta intrincada red que constituye el pensamiento político de principios del siglo XIX.

En una sociedad atravesada por grandes cambios a nivel económico y social, el concepto de "capacidad" es visualizado como posible fuente de orden. Algo similar advierte Sheldon Wollin al referirse a otra de las corrientes en crecimiento por ese entonces: el saintsimonismo. $\mathrm{Y}$ dicha similitud permitiría reconocer algunos puntos de confluencia entre el saintsimonismo y el liberalismo doctrinario. Tal como lo explica Wollin, el problema de la organización, es, junto con el de la comunidad, el problema central del siglo XIX, y ello es el resultado no sólo de la Revolución sino también de los importantes cambios operados en materia científica e industrial. En este marco debe inscribirse a una figura como la del Conde de Saint-Simon, que recurre a la industria como modelo de organización con una nueva estructura de poder y una jerarquía bien definida, y propone una nueva estructura para la sociedad: "el orden industrial sería el antídoto contrarrevolucionario a la agitación de las masas". 9 Tal cosa repercutiría sobre la política, hasta tal punto que ésta parece desaparecer bajo el dominio de los "principios científicos" que, basados en la naturaleza humana, se

\footnotetext{
${ }^{7}$ Ibid., p. 91.

${ }^{8}$ Ibid, p. 310.

9 Wollin, Sheldon, Politica y perspectiva. Continuidad y cambio en el pensamiento politico occidental, Buenos Aires, Amorrortu, 2001, p. 405.
} 
pretenderían independientes de la voluntad ${ }^{10}$. El saintsimonismo podía consolidarse, entonces, a veces como un complemento, a veces como una opción a los tintes reaccionarios de los que se iba tiñendo el liberalismo. Como lo sostiene Wollin, "la supremacía de la sociedad y la necesidad de autoridad, formaron un estribillo repetido al infinito durante todo el siglo, un coro muy heterogéneo" 11.

Según este crítico, el liberalismo clásico había alimentado los impulsos antipolíticos del siglo XIX. La mayoría de los proyectos del siglo XIX excluían la actividad política de la vida de la sociedad y el punto de partida para esa exclusión fue la tajante separación entre las actividades políticas y las privadas. La racionalidad reinante era socioeconómica, la acción política no podía modificar su carácter, ni la teoría política comprenderla. El carácter político de la sociedad había sido destruido por el avance del Estado, que iba unido al gradual aislamiento de los individuos. Pero, al mismo tiempo, en muchos casos, esa organización que se imponía se presumía democrática, haciendo del obrero una "parte" de ella: "el administrador es responsable de los procesos vitales de un 'sistema político'. Para cumplir con eficacia sus fines, es menester que logre el 'consenso' de sus miembros". Pero "consenso" no implica autogobierno, sino más bien "compromiso", y "compromiso" es allí algo particular: "es la receta especial para una época de masas en que los hombres se hallan aislados y sus vidas despersonalizadas y tristes" 12 .

La cercanía entre el liberalismo y el saintsimonismo también es observada por Bénichou, aunque en términos diferentes a los de Wollin. Bénichou reconoce, entre los motivos más recurrentes del liberalismo del siglo XIX, la permanente tentación de afirmar un orden universal sobre el cual fundar el progreso. Aunque rechacen la idea de un "dogma social", afirmando que el único dogma es el de la libertad, para los liberales las

\footnotetext{
10 Wollin advierte la relación de estas posiciones con la "teoría constitucional", en cuyo marco reconoce a Royer-Collard, para quien es preferible referirse a "soberanía constitucional" antes que a "soberanía del pueblo", dado que aquella nos remite a derechos e intereses, desapareciendo todo lo rclativo a las individualidades. Véase ibid, p. 421.

11 Ibid, p. 421.

12 Ibid., 462.
} 
nociones de razón, verdad y justicia poseen un valor positivo al ser condición de posibilidad de la afirmación del progreso. Se trataría, según él, de la afirmación de una "fe progresista"

Sin embargo, Bénichou destaca las diferencias del liberalismo respecto de las otras posiciones, considerando como rasgo prioritario el hecho de que el liberalismo se asiente sobre la base de la valoración de la libertad como principio rector de lo humano. Analiza las críticas que los liberales dirigen a la apelación saintsimoniana a un poder espiritual y a la valoración del progreso como obra de una voluntad divina que garantizaría el cumplimiento del destino colectivo, destino que sobrepasa al de los individuos. En la medida en que tales afirmaciones entran en contradicción con aquella libertad que era central para los liberales, Bénichou mismo toma posición y ensaya una fuerte crítica al saintsimonismo y a las diversas posiciones que se derivaron de esta corriente.

Aquel requerimiento de un poder espiritual es la estrategia que los pensadores de la utopía adoptan para hacer frente al mundo burgués. Según él, el saintsimonismo impugnaba la sociedad asentada sobre los intereses individuales y sobre una moral personal. En contra de ella, postulaba el dominio de un "dogma" y su compromiso con la realidad social. Aquel dominio contradecía, según Bénichou, la tan deseada libertad. Sin embargo, este autor destaca otro motivo en su crítica al saintsimonismo: ese compromiso con la realidad social permanecía en el nivel del discurso sin hacerse efectivo, siendo evidente la distancia entre las formulaciones utópicas y los intereses del pueblo. Tal como él mismo lo enuncia, "si se busca a través de las construcciones sucesivas de la utopía, qué vínculos estableció con los diversos medios sociales, no se encuentra en absoluto que la inspiración popular y obrera le fuera congénita"14.

Pasando en limpio los elementos más relevantes en esta rápida caracterización de Bénichou respecto del pensamiento político francés de la primera mitad del siglo XIX y de algunos juicios que han recaído sobre éste, podemos decir que ambas posiciones, el liberalismo y el saintsimonismo se

13 Bénichou, Paul, op. cit., p. 354.

${ }^{14}$ Ibid, p. 302. 
asientan sobre un suelo común: la experiencia de la Revolución ${ }^{15}$. Ambas recibieron la herencia del siglo XVIII y de la Revolución y, con ella, la idea de que

los destinos sociales son los del conjunto de los hombres, la inmensa mayoría del cual la componen los humildes y los oscuros. No prestar atención a esa muchedumbre, es necesariamente falsear la verdad. Pero de la atención a la reverencia, a la comunión, al encomio son grandes las distancias y numerosos los grados ${ }^{16}$.

Tanto el humanitarismo como el liberalismo atendían el reclamo del pueblo pero de diferente modo. Para los liberales el pueblo representaba esa masa de necesidades a las que había que atender. Para los humanitaristas, el pueblo era una "comunidad viviente", digna de adoración y adulación.

Tal como lo lee Bénichou, el humanitarismo conducirá, tarde o temprano, incluso sin desearlo, a la negación de la libertad y podrá traducirse, después de 1848, en formas cercanas al absolutismo.

15 Bénichou llega incluso a afirmar que "la diferencia entre el liberalismo y el humanitarismo, que son a fin de cuentas, hasta 1848 , las dos tendencias dominantes de la opinión intelectual, es considerable en el plano de la acción concreta y de los fines concretos; en el plano puramente filosófico se muestra más difícil de captar, porque las dos doctrinas no están separadas por una oposición radical de principios, sino más bien por una dosis distinta de los mismos elementos" (ibid, p. 356). Aclaremos que al decir "humanitarismo" Bénichou se refiere a una corriente filosófico-política que, si bien excede el saintsimonismo, lo incluye. No obstante, Bénichou no es claro respecto de los límites entre ambas líneas de pensamiento y, a menudo, tiende generalizar para todo el llamado "humanitarismo" las características otorgadas al saintsimonismo.

${ }^{16} \mathrm{Ibid}$, p. 356. Advirtamos que en esta afirmación Bénichou parece regresar sobre sus propios pasos, diluyendo la particularidad del humanitarismo respecto del saitsimonismo a la que él mismo se refería en términos de maridaje entre el espíritu de la utopía y el partido democrático. Por otra parte, recordemos nuevamente que la imagen del liberalismo que ofrece no atiende a la distinción que hicimos arriba entre el liberalismo de Constant y el de Guizot. 
Al ensalzar la libertad y la conciencia individual sin situarlas claramente frente a lo que, en la ideología contemporánea, podría contrariarlas, el humanitarismo se desarmó ante el retorno de la utopía totalitaria, exponiéndose de antemano a sufrir su fascinación. Es lo que se produjo con la difusión del marxismo, y sobre todo lo que se designa con este nombre desde 1917: una nueva filosofía de la necesidad histórica, formulada en pretendidas leyes de la ciencia y que conduce a un absolutismo político sin apelación, ha gozado esta vez de un público lo bastante amplio para pesar sobre el destino de la humanidad ${ }^{17}$.

Aquello sobre lo que se asienta, en definitiva, el juicio condenatorio de Bénichou, es la posibilidad de extraer de la afirmación saintsimoniana o humanitarista de la humanidad la idea de una salvación providencial, necesaria, doctrinal y colectiva.

De este modo, nos encontramos aquí con una descripción similar a la que ofrecía Wollin respecto de las consecuencias del saintsimonismo, y si en términos generales, contextualizando estas posiciones del siglo XIX y los acontecimientos que les siguieron, no podemos dejar de atribuir a tales juicios algún valor de verdad, por relativo que sea, es interesante reconocer la posibilidad de revisar esas formulaciones desde otro lugar. En este sentido, es significativa la lectura que ofrece Miguel Abensour. Abensour denuncia la mirada esquemática y reductivista que permite a Bénichou reconocer en el recurso de la "utopía pseudocientífica" un dogma nuevo destinado a la reunificación de la sociedad dividida, una utopía dogmática que conduciría de manera necesaria al sostenimiento de un modelo político autoritario. Aquello que parece motivar la crítica de Bénichou a los utopistas es la concepción de la religión que está a la base de su interpretación. Según Abensour, en la obra de Bénichou la dimensión religiosa no es nunca apreciada en cuanto tal, es sólo un efecto secundario, sin autonomía ni intencionalidad verdadera ${ }^{18}$.

Distanciándose de esa visión, Abensour afirma que la tarea misma de la interrogación filosófica consiste centralmente en "dejar emerger las

17 Ibid, p. 530.

${ }^{18}$ Véase Abensour, Miguel, "L'utopie socialiste: une nouvelle alliance de la politique et de la religion", en Le temps de la réflexion, tome II, Paris, Gallimard, 1981, p. 68. 
formas de conciencia, las prácticas, los tipos de inversión pasional de los actores mismos del siglo diecinueve que en su elán hacia un nuevo mundo, no separaban la cuestión religiosa de la de la emancipación"19. Ese vínculo entre religión y emancipación permite a Abensour reconocer el rasgo particular del saintsimonismo o socialismo utópico.

Si bien la denuncia de la búsqueda de una fórmula superior de comunidad humana es lo que permite a autores como Bénichou ligar el socialismo utópico con las formas del autoritarismo y, más precisamente, con el fascismo - socialismo y fascismo son agrupados en una misma categoría que se desprende del hecho de que ambas posiciones serían expresiones de la búsqueda de lo que George Mosse denomina "nueva política"-, es justamente esa búsqueda el eje de la defensa que sostiene Abensour. Mientras en un caso, el del socialismo, las pasiones y la búsqueda de una "fórmula superior de comunidad humana" se despliegan armónicamente en un movimiento hacia el futuro, en el otro, el del fascismo, aquéllas son concebidas como una reacción subversiva de la naturaleza que rechaza la trascendencia ${ }^{20}$.

De este modo, la utopía, la apelación a la religión y la vinculación de ésta con la política se presenta, en Abensour, en el extremo opuesto a las diversas formas de autoritarismo de los siglos XIX y XX: como apertura a una trascendencia que impide la clausura totalitaria del horizonte históricopolítico. De ahí su valoración del saintsimonismo. La utopía es la continuación de la Revolución por otros medios. En Saint-Simon, por ejemplo, se trata de la revolución científica, que sucede a la revolución política, abriendo un nuevo destino para el movimiento de la emancipación. Pero lo que se destaca aquí es que al "espiritualizar la cuestión revolucionaria, al sublimarla, se trata de efectuar un paso de una revolución unidimensional a una revolución (...) que pone lo político sobre órdenes que lo sobrepasan y lo engloban" 21 .

Lo que puede encontrarse en Saint-Simon, leído bajo esta luz, es la ampliación de la esfera política, que ahora se encuentra con un nuevo

\footnotetext{
19 Ibid, p. 69.

${ }^{20}$ Véase Ibid, pp. 73-74.

${ }^{21}$ Ibid, p.77.
} 
dogma, desprendido de la ciencia. Lejos de lamentar el avance de la ciencia y de la industria y de detenerse en la crisis de la modernidad, Saint-Simon encuentra allí mismo los motores de la historia y su progreso. La religión deviene ciencia, en la medida en que ambas, religión y ciencia, son consideradas representaciones de la unidad. La religión, fiel a su vocación política, busca una nueva forma de revelación con mayor eficacia política, y el legislador moderno se convierte ahora en científico ${ }^{22}$.

Se podría hablar, entonces, dice Abensour, de una "nueva política" entre los utopistas, aunque con un sentido diverso al que evocaba Bénichou. Si el jacobinismo podía recibir del doctrinarismo una condena basada en su anacronismo, quedaba todavía una opción que no implicaba necesariamente el abandono de la política.

¿Es verdad que, a causa de la complejidad del mundo moderno, de su repliegue sobre lo privado, de la complejidad de las relaciones sociales, cl tiempo de los legisladores ha caducado? Tal es la pregunta que estamos en condiciones de enunciar y la verdad de esta nueva política es el haberla formulado, el haber puesto el dedo sobre lo que parecía ser la impotencia y la estrechez del pensamiento liberal ${ }^{23}$.

Para Abensour, en otros términos, el saintsimonismo se resistía a la clausura de lo político en lo privado, al fin de la política y a su absorción en procesos sociales. Sin embargo, no todo es novedad y no todo está exento de crítica en el saintsimonismo a los ojos de Abensour, quien nos remite a aquella distinción tan frecuente entre los saintsimonianos entre "épocas críticas" y "épocas orgánicas", de edificación y construcción. El rechazo de las "épocas críticas" y el convencimiento respecto de estar viviendo una "época orgánica", de la cual ellos mismos serían los protagonistas, nos obliga a revisar el modo en que los saintsimonianos presentan aquella alianza entre la religión y la política. El problema aquí no es, como sostenía Bénichou, la alianza misma, sino el modo en que ésta se da. El problema es que entre los saintsimonianos, el ámbito político es ocupado por una nueva teocracia cuya posible relación con una cultura política autoritaria merece ser

22 Véase Ibid, p. 83.

${ }^{23}$ Ibid, p. 86. 
atendida. En relación con esto, Abensour se pregunta: “¿cómo interpretar el privilegio que los saint-simonianos han dado a las épocas orgánicas (...) sino como voluntad de poner término a la movilidad democrática, signo de cuán negativas son las épocas críticas?" 24 . La religión resulta, entonces, una herramienta de la política puesta al servicio del control social.

Sin negar de manera radical la posibilidad de hallar en el saintsimonismo un valioso aporte para repensar la política moderna en el siglo XIX, estas características de la escuela nos permiten mirar un poco más allá de ella y reconocer la particularidad de la llamada "disidencia saintsimoniana". Tal como lo advierte Abensour, su aspecto "disidente" no alcanza a dar cuenta del singular lugar que esta línea ocupa en el escenario que estamos analizando y de las consecuencias que acarrea a nivel políticointelectual.

Dentro de esta disidencia se destaca la figura de Pierre Leroux, sin que ello implique soslayar otros nombres tales como los de George Sand y Jean Reynaud, entre otros. Para Leroux, dice Abensour, "el trabajo de la filosofía en el campo de la utopía se ejerce en direcciones múltiples: preservar un sentido de la complejidad, luchar contra la homogeneización y, más allá, no ceder a la ilusión del dominio" 25 . Leroux representa un momento de "apertura filosófica" que pone de manifiesto la potencialidad del socialismo naciente en términos de emancipación. Privilegiando la vida, pero no la vida individual sino la vida de la humanidad, la vida intersubjetiva, la filosofía de Leroux aparece como una base para pensar la política moderna más allá de la "libertad de los modernos" y sin recurrir a las formas anacrónicas o autoritarias de la "libertad de los antiguos".

Tal como sostiene Abensour,

según Leroux es conveniente efectuar una síntesis entre la emancipación (el momento del racionalismo y de la subjetividad, Descartes), la idea de correspondencia o relación (la filosofía política clásica, el hombre como ser político) y la idea de sucesión (la teoría de la perfectibilidad, Perrault, Pascal,

\footnotetext{
24 Ibid, p. 92.

${ }^{25}$ Ibid, p. 96.
} 
Malebranche, Condorcet, Lessing, es decir, el paso de una filosofía social a una filosofía de la historia) ${ }^{26}$.

El movimiento de la historia es un movimiento de emancipación llevado adelante no por fuerzas sobrenaturales, porque tal cosa sería atentar contra la libertad, sino por los hombres mismos constituidos históricamente. En el marco de este ambicioso proyecto, la religión no habrá de desaparecer sino todo lo contrario. Leroux persigue la síntesis entre filosofía y religión: una filosofía que no existe sino como creencia. Una filosofía que es ciencia de la vida, atenta al presente pero que, al mismo tiempo, requiere encarnarse en la sensibilidad más profunda, reconoce inmediatamente el fundamento de su objeto en una imagen divina, que es Dios, pero también la humanidad. Sobre esa base habrá de pensarse también la relación entre la religión y la política. La religión, en Leroux, es la condición de la democracia.

La alianza entre la política y la religión, sostiene Abensour, se establece, en el saintsimoniano disidente, sobre una base suficientemente rigurosa para evitar la constitución de un nuevo nexo teológico-político. Se trata, simplemente, "de permitir que un grupo humano que, reunido sobre un mismo territorio de consideraciones de utilidad, se eleve al nivel de un pueblo o, mejor dicho, conquiste en tanto que pueblo su unidad y su identidad. Espejo en el que se refleja un sujeto político colectivo, la religión será el lugar estético en el que, por los símbolos, las ceremonias y las fiestas, se dará libre curso a la comunicación política"27.

Pero es interesante advertir que la apelación a la religión no es, en ese esquema, una apelación utilitaria. En la lucha moderna contra el cristianismo, Leroux percibe un "movimiento de sacralización de la historia humana", un movimiento por el que el hombre se afirma en esa capacidad de "reconciliar la autoinstitución de la humanidad, de Dios o de lo absoluto" 28 . El recurso de Leroux a la religión es aquello que aproxima la utopía a los ideales emancipatorios modernos, poniendo de manifiesto la posibilidad de reconciliar lo finito con lo infinito.

\footnotetext{
${ }^{26}$ Ibid, p. 98.

${ }^{27}$ Ibid, pp. 104-105.

28 Ibid, p. 105.
} 
Con la ayuda de Abensour se puede, entonces, reconocer nuevos matices en el pensamiento político y filosófico francés del siglo XIX, y una opción real y no regresiva respecto del liberalismo, que si bien permite destacar a Leroux como una figura central no se limita sólo a sus formulaciones. En este marco, hemos de extender las consideraciones de Abensour hacia parte de aquello que Bénichou llamaba "las versiones más populares del humanitarismo", advirtiendo la productividad de algunas de sus formulaciones como expresión de la necesidad de repensar, en términos de emancipación, el modelo político que se desprendía de aquel advenimiento de la "libertad de los modernos"29. Esta filosofía, fiel retrato del debate político en torno a las posibilidades de la democracia que atraviesa el siglo XIX, no sólo ofrece un diagnóstico de la situación francesa hacia mediados de siglo, sino que es, además, un interesante intento de responder a la crisis filosófica, política y social que surge del vacío de fundamentos trascendentes junto a la implacable necesidad histórica de hacer reales los principios de 1789.

\section{La "filosofía" de Pierre Leroux}

Repasemos en lo que sigue algunos aspectos de las formulaciones de Leroux respecto de la filosofía que podrían ayudarnos a pensar en la revalorización propuesta por Abensour.

Leroux es una de las figuras más sobresalientes de la historia del socialismo, denominado por Marx y Engels, utópico. Fue fundador, en 1824, junto con Dubois, de Le Globe, en donde permaneció hasta 1830, año en que comienza a alejarse de las filas liberales para acercarse a los discípulos de Saint-Simon que publicaban ya sus ideas en L'organisateur, "periódico saintsimoniano que prepararía el advenimiento de una nueva sociedad

29 Sin especificar, Bénichou reconoce una particularidad dentro de la posición saintsimoniana: "las luchas populares y obreras la desviaron y modificaron de acuerdo con sus propias tendencias, sin dejar de inspirarse poco a poco en ellas. (...) La unión de la utopía no debía hacerse sino a tientas. El saintsimonismo, antes de encallar en su iglesia, había visto destacarse de él, casi desde los comienzos, a unos hombres que habían de maridar el espíritu de la utopía con el del partido democrático, y formular así una de las versiones más populares del humanitarismo" (Ibid, p. 303). 
orgánica y religiosa"30. Junto al grupo de los llamados "pontífices" saintsimonianos permaneció sólo un año, al cabo del cual se alejaría con un juicio crítico respecto de la lógica autoritaria reinante en la secta. De aquí en más su posición se irá consolidando en la búsqueda de una nueva opción frente a los principales movimientos filosóficos y políticos de la época, respecto de los cuales ya había descubierto sus principales diferencias. La nueva opción perseguida por Leroux tiene en estos años como principales órganos de difusión a la Revue Encyclopédique, fundada en 1831 por él mismo, Carnot y Reynaud, y a la Revue Indépendante elaborada junto a Georg Sand y Louis Viardot, publicaciones que aportaron, por otra parte, el material de sus principales libros.

Dos son, en nuestra lectura de la obra de Leroux, los ejes a partir de los cuales se puede organizar la infinidad de problemáticas y aristas que aborda: la historia y la filosofía ${ }^{31}$. Se trata de una lectura histórica de la Francia contemporánea y se trata también de una concepción de la filosofía y de su tarea. Lo que importa, en ese marco, es resaltar el valor histórico de una filosofía aún no reconocida.

Una idea, dice en 1831, resume el siglo XVIII: "los filósofos han dicho a los reyes, a los nobles, a los sacerdotes 'ustedes no son los más dignos para gobernar. Pues no son ni los más queridos, ni los más inteligentes, ni los más laboriosos"' 32 . Mientras que la política antes pasaba por la nobleza o la iglesia, ahora, después de 1789, se liga al pueblo, a los ciudadanos y tiene un principio -la igualdad-, un objetivo -la libertad-y un modo de realizarse -la fraternidad. No obstante, la historia de Francia debió esperar hasta julio de 1830 para verse encaminada hacia el objetivo buscado. En julio, afirma Leroux, se observa que "un nuevo orden social comienza", aunque tal cosa no implique que entonces el objetivo se alcance. Si bien es cierto que 1830 representa una diferencia respecto de la política de Napoleón y la Restauración, no por ello es la conclusión de aquello que se habría comenzado en la Revolución a fines del siglo anterior. Y, aunque el

30 Viar, Bruno, "Introduction", en: Leroux, Pierre, De l'égalité, Paris, Slatkine, 1996, p. 8.

${ }^{31}$ Nos atenemos aquí a los trabajos desarrollados por Leroux en las décadas del $30 \mathrm{y}$ del 40.

${ }^{32}$ Leroux, Pierre, Aux philosophes, aux artistes, aux politiques, Paris, Payot, 1994, p. 75. 
juicio de Leroux sobre la revolución de Julio vaya mutando con los años, hasta llegar a ver el nuevo régimen como una restauración ${ }^{33}$, desde sus primeros escritos sobre el tema se cuidará de exagerar su valor.

Son razones de distinta índole, teóricas, políticas y sociales, las que en diferentes pasajes están a la base de la crítica dirigida, no tanto al acontecimiento revolucionario, cuanto al curso que éste siguió. Con la política implementada después del 30, reina en Francia la incertidumbre; el hombre ha quedado solo, aislado, y la sociedad se fragmenta bajo el dominio de la desigualdad. La tarea del filósofo, del mismo Leroux, se inscribe en este marco: un desarrollo teórico que tiende a revisar los supuestos ideológicos de aquella realidad y postular un nuevo punto de partida. La tarea del filósofo, íntimamente vinculada a la del periodista, consiste en distinguir los órdenes de lo existente y conservar la posibilidad de reconocer un sentido en la complejidad de lo real y de su heterogeneidad ${ }^{34}$.

La necesidad de un "dogma" que domine sobre el conjunto de la sociedad ocupa, en la obra de Leroux, un lugar privilegiado. Se parte de un diagnóstico: la incertidumbre reinante. Lo más cierto, dice jugando con las palabras, es la incertidumbre respecto de todo. El hombre no sabe qué es la virtud, qué es la verdad, qué es el deber ${ }^{35}$. Pero en el comienzo también encuentra una certeza: la filosofía debe responder a la necesidad de su época y, desde allí, marcar una ruta que pueda servirle al hombre. Tal respuesta habrá de asentase necesariamente en un principio, en un punto fijo. Ese es su axioma inicial. La filosofía, así entendida, debe y puede destronar a la incertidumbre.

Tanto en el artículo publicado en 1831 que lleva por título "Aux Philosophes", cuanto en la primera parte de la "Réfutation de l'éclectisme" de $1838^{36}$, Leroux se ocupa con cuidado de esta cuestión, presentando entre

${ }^{33}$ Véase Leroux, "De la Philosophie et du Christianisme" (1832) en: Ibid, p. 194. ${ }^{34}$ Vésae Abensour, Miguel, Le procès des maîtres rêveurs, Arles, Sulliver, 2000, p. 83. ${ }^{35}$ Leroux, “Aux philosophes" (1831-1841), en: Leroux, op. cit., 1994, p. 121. 36 "Aux Philosophes" es el nombre de un artículo publicado por primera vez en 1831, en la Revue Encyclopédique, arreglado y completado en 1841 para la Revue Indépendante, reimpreso en 1847, luego en 1850 en el tomo I de las Obras completas y finalmente en la compilación con la que hemos trabajado aquí, Aux philosophes, aux artistes, aux politiques. "Réfutation de l'éclectisme", por su parte, se refiere a un 
ambos escritos tesis complementarias. A partir de su interés por definir el rol de la filosofía y distanciarla de aquella caracterización que los eclécticos ofrecían en la Universidad ${ }^{37}$, Leroux liga la filosofía con dos ámbitos que, claramente diferenciados entre sí en un principio, terminarán por presentarse en estrecha relación. En primer lugar se destaca el vínculo de la filosofía y su época. La filosofía no es más pensamiento abstracto. Su material deriva, en parte, de la historia de la filosofía y, en parte, de las necesidades de su época. "Todo filósofo participa necesariamente de los trabajos anteriores de la Filosofía. Pero nadie es filósofo si no hace sufrir a dichos trabajos una modificación importante" 38 . Y esto se debe a que la filosofía "es la ciencia de la vida" 39 , siempre trabaja con objetos eternamente mutables: el hombre, la naturaleza. La filosofía debe articular una alianza entre teoría y práctica. Dice Leroux:

la filosofía tiene siempre, en efecto, el doble carácter de partir de las cosas más comunes y de los hechos más ordinarios, para volver después de un inmenso rodeo (...). No hay ninguna cuestión de vida práctica, por más simple que se la imagine, que no arrastre nuestro espíritu a sondear los misterios más profundos, y que no nos conduzca a las más difíciles preguntas de la filosofía y, recíprocamente, los dogmas de la filosofía tienen por blanco la práctica misma de la vida ${ }^{40}$.

En este sentido, sus respuestas son relativas, los "monumentos filosóficos" -así llama Leroux a las grandes obras y autores- sólo tienen vida

conjunto de artículos publicados inicialmente en 1833, en la Revue Encyclopédique, y en 1838 en la Encyclopédie Nouvelle, y posteriormente reunidos en un libro: Réfutation de l'éclectisme, para su publicación en 1839.

${ }^{37}$ Algunos de los principales teóricos doctrinarios, entre los que se destacan Cousin y Jouffroy, ocupan, por ese entonces y de manera exclusiva, las cátedras de filosofía en París. Se los conocerá como los "filósofos de la Universidad". Sobre esta cuestión, véase: Vermeren, 1995.

${ }^{38}$ Leroux, Pierre, Réfutation de l'éclectisme, Genève, Slatkine, 1979, p. 10.

${ }^{39}$ Ibid, p. 22.

${ }^{40}$ Abensour, Miguel, "Comment une philosophie de l'humanité peut-être une philosophie politique moderne?", posfacio a Leroux, P., 1994, Aux philosophes, aux artistes, aux politiques, Paris, Payot, 1994, p. 296. 
mientras las necesidades de los hombres los requieran. El hombre piensa, pero además siente, vive, actúa y al hacerlo modifica constantemente su pensamiento. La filosofía, entonces, siempre recomienza.

En el otro extremo, Leroux reclama la identificación entre filosofía y religión. Toda filosofía es implícitamente una religión que acompaña, guía y hasta da sentido a la vida de la humanidad. Leroux se refiere a "la virtualidad creadora de la idea del filósofo", capacidad que convive con "la virtualidad creadora de la humanidad que recibe esta idea". Entendida bajo el prisma de la religión, la filosofía reclama un sistema en el que la tradición y la historia de la filosofía ocupen un lugar privilegiado. La filosofía conjuga la novedad, que se construye en relación con las necesidades inmediatas de una época, con la necesidad de una base firme, un principio, un punto inicial. Esta conjunción de extremos es lo que hace de la filosofía el bien más preciado de una época, de la modernidad; es lo que hace de la filosofía una respuesta a la incertidumbre. Pero Leroux insiste una y otra vez: "la religión del futuro no será el cristianismo" 41 . En ello hace hincapié también Abensour al recordar la lectura que Leroux hace de Schelling: Leroux puede reconocer en Schelling una visión reaccionaria, al destacar que el alemán ve en el cristianismo una vía aún abierta. No obstante hay también en Schelling un valor innegable para el francés: la importancia asignada a la revelación. La revelación, dice Abensour parafraseando a Leroux, "ofrecería un alma a la filosofía", y, citando a Leroux, agrega, "sí, el cristianismo es un hecho divino, como dice Schelling. Solamente agregamos: es un hecho que será seguido de otro hecho no menos divino que él" 42.

Leroux conjuga la firmeza de un sistema que se desprende de una concepción de la historia como continuo perfeccionamiento de la humanidad, con la relatividad de los aportes particulares que no ofrecen más certeza que aquella que se obtiene del consentimiento y del sentimiento individual o la conciencia ${ }^{43}$. Así, por ejemplo, al referirse al cristianismo y en particular a la encarnación del verbo divino en Jesús, Leroux destaca tanto la necesidad de afirmar cuanto la de negar su verdad, "porque en este orden de verdades

\footnotetext{
${ }^{41}$ Leroux, P. Aux philosophes, p, 166.

42 Abensour, Miguel, "L'affaire Schelling", Corpus, Revue de philosopbie, n 18-19, 1991, p. 128.

4.3 Véase Leroux, P., Réfutation, p. 115.
} 
sí y no no son contradictorios". ${ }^{44}$ Aquella afirmación no es falsa sino en el sentido en que nosotros podemos darle hoy otra formulación, agrega, esto es: que todos somos hijos de Dios y que el ideal divino puede encarnarse en todos los hombres ${ }^{45}$. Así, se pasa de una proposición particular a una universal. La tarea, entonces, será "buscar las consecuencias de esos dos grandes movimientos generales de la humanidad [al cristianismo se le suma aquí el naturalismo. M.C.G.], buscar la verdad relativa a nuestra época" ${ }^{46}$. De esta manera la filosofía ocupa el lugar que otrora ocupaba la religión, pero reconociendo, no obstante, la fragilidad de cada formulación, su sujeción al cambio, su condición epocal.

El diagnóstico respecto de la crisis por la que atraviesa la sociedad y la política francesa permite reconocer más de cerca esta relación de la filosofía con la religión. Si Leroux encuentra una sociedad destruida por la falta de certeza y por la exacerbación del individuo, puede explicarlo por la filosofía reinante hasta el momento. La posibilidad de revertir este estado de cosas también podría ensayarse, entonces, de la mano de la filosofía. Sin rechazar de plano la Edad Media, pues tal cosa supondría contradecir la idea de progreso continuo, de "perfectibilidad indefinida" de la humanidad, Leroux reconoce la importancia y la radical novedad del siglo XVIII y en particular de 1789. El movimiento de la historia debe explicarse del mismo modo que entendemos la vida, es decir, como un permanente suceder de cambios a través de una serie continua que conduce finalmente a la muerte, sin que ello implique la negación de lo anterior, puesto que algo permanece con los cambios y algo renace después de la muerte. Un constante suceder de épocas quie se contienen unas a otras. Hay momentos de quiebre -1789 es uno de ellos- pero éstos no implican la rotunda negación del valor de la época anterior. He aquí la principal crítica de Leroux a la Revolución. Es claro que ésta es el más grande acontecimiento ocurrido en Francia, que hasta el momento nada igual había tenido lugar en su historia, "es la era de Voltaire" 47 , exclama animado. No obstante la Revolución trajo consigo la negación de la religión. El curso adoptado por la Revolución con el correr

\footnotetext{
44 Ibid, p. 35.

${ }^{45}$ Véase ibíd. p. 37.

46 Ibid, p. 39.

${ }^{47}$ Leroux, P., Aux philosophes, p. 80.
} 
de los años y en particular después del 30 hizo imposible que la sociedad reconstruyera alguna base sólida para su edificio de creencias, alguna base sólida sobre la cual mantenerse en pie.

Con esto Leroux afirma que el pensamiento humano es uno, aunque sea al mismo tiempo social y religioso, como "dos caras que se corresponden y engendran mutuamente" 48 . En la Edad Media cielo y tierra se complementaban mutua y necesariamente, aquello que el hombre no tenía en la tierra podía esperarlo en el cielo. En el cielo reposaban las promesas de igualdad, de justicia, de felicidad y el hombre en vida podía pensarlas como posibles. Del mismo modo, el pecado original explicaba y hasta justificaba la desigualdad en la tierra. La figura de Jesucristo mediaba entre la culpa y el Paraíso. A pesar de la fuerza que poseía, ese edificio fue derrumbado. Leroux se sorprende frente a la imagen de una sociedad que habría podido salir de él, pero lo que esconde tal sorpresa es, en el fondo, una certeza y una denuncia. En primer término, la humanidad no puede vivir sin dogma, el dogma es garantía de sociedad. Sin él, reina el caos y la esclavitud. La Revolución hizo posible al hombre despojarse de todo consuelo futuro para los sufrimientos actuales, de toda imagen legitimada del dominio de unos sobre otros, pero en la medida en que la Revolución no trajo consigo el fin de las desigualdades y de la tiranía de los gobiernos, estos sufrimientos sin consuelo no podrían sino convocar el caos.

Se cruzan en esta descripción dos elementos: la denuncia de un estado de cosas atravesado por la desigualdad y el sufrimiento, con un fuerte sentimiento de pérdida por la carencia de religión. A menudo pareciera que Leroux reclama un consuelo para aquel sufrimiento, consuelo que sólo vendría de la mano de la religión. No obstante, tal cosa no implica el regreso a la Edad Media, a sus costumbres, a sus ideas, a su forma de vida. Leroux insiste una y otra vez en el valor de 1789, en la apertura de una nueva época que, si bien aún falta concluir, no puede anularse. De lo que se trata es de reconocer la necesidad histórica de esa época iniciada entonces, y esa necesidad es doble para el filósofo: la concreción material del principio de la igualdad y la realización efectiva de una sociedad según el modelo de la fraternidad.

48 Ibid, p. 83. 
El hombre moderno descubre la arbitrariedad de las diferencias y desde allí estaría habilitado para reclamar por su situación. Después del siglo XVIII el hombre moderno puede reclamar la realización de aquello que postula la ley. Pero he aquí el principal problema que observa Leroux, el hombre sólo puede reclamar aisladamente, el hombre es ahora un individuo aislado que responde a instintos egoístas porque se lo ha despojado de todo, se lo ha dejado sin dogma, sin creencias, sin fe o principios compartidos que den cuenta de su inscripción en un todo social y hasta natural o genérico. La sociedad ha sido destruida, "la duda insensata recorre y surca la tierra en todos los sentidos"49, la duda, sembrada en un momento para dar fruto, se ha instalado y ha dividido a los hombres. ${ }^{50}$

De este modo lo recuerda Leroux en su artículo "De l'individualisme et du socialisme" de 1833. Allí, los desarrollos teóricos se ligan con un reclamo social. Reivindicando las ideas revolucionarias, recuerda los principios de libertad, igualdad y fraternidad, y en este marco rescata la negación de los revolucionarios a imponer un sistema social definido. Ellos habrían planteado, afirma Leroux, que "la sociedad debe satisfacción a la individualidad de todos, es el medio para la libertad de todos" 51 . Y de allí que el sentimiento de libertad propio del siglo XVIII no puede anularse pretendiendo regresar a la devoción cristiana. "Sería retrogradar el querer organizar hoy despóticamente la sociedad según las visiones particulares que podemos tener, en lugar de fundarlas sobre el principio de la individualidad y la libertad" 52 . Este argumento, ya lo adelantamos, deja abiertas las puertas para el reclamo social. Aquella descripción que postula el fin de los privilegios en nombre de la libertad tiene como corolario, en su cumplimiento, la realización de la igualdad social. Sin embargo, lo decía ya en 1831, esa igualdad no se ha realizado, aún hay quienes reclaman la obediencia de otros, aún hay quienes legitiman el deber de algunos a obedecer.

\footnotetext{
49 Ibid, p. 89.

${ }^{50}$ Sería interesante recordar aquí la crítica de Leroux a la lectura que ofrece Cousin de Descartes. Según Cousin, en la duda se cifraría y reduciría todo el pensamiento de Descartes. Para Leroux, la duda es afirmada en función de una certeza.

51 Ibid, p. 244.

52 Ibid, p. 244.
} 
Más que una descripción de un estado de cosas, encontramos aquí una denuncia que puede leerse también desde la tematización de la filosofía misma, de su objeto, su método y sus objetivos. Al plantear la relación de la filosofía con el dogma, Leroux está discutiendo con aquella filosofía de la Universidad que mencionamos antes, destacando el fuerte poder que sus formulaciones tienen sobre la sociedad francesa. Si en última instancia es necesario reclamar un dogma, algo que ligue a los hombres, esto se debe al contundente efecto de aislamiento que aquella filosofía tiene sobre los individuos.

El eclecticismo es, según Leroux, una "filosofía de la naturaleza" y una "filosofía del inmovilismo". A partir de alli se desarrollan las críticas. El método utilizado por Cousin es el de los naturalistas, el de Bacon, el de Condillac ${ }^{53}$. Sin embargo, ese naturalismo reconocía un límite en su incapacidad para aplicar este método a los fenómenos no físicos. Cousin, al contario, no encuentra problema alguno en concebir la filosofía de acuerdo con el modelo de las ciencias físicas o naturales. Si conservamos la distinción alemana, dice Leroux, entre lo objetivo y lo subjetivo para juzgar el conocimiento, con la afirmación de Cousin debemos suponer que la "vida subjetiva" se hará sentir de manera "directamente objetiva", como la vida de las plantas o de los animales. Es necesario, en cambio, sostiene nuestro autor, distinguir tres órdenes de existencia reconociendo que cada orden posee un criterio distinto de certidumbre. Para un primer orden, el de la vida del mundo exterior al hombre, debe recurrirse a la experiencia $u$ observación. Para el segundo, el de la vida humana individual, el criterio es el razonamiento. $\mathrm{Y}$ para el tercero, aquel que contiene a la vida humana

53 Una rápida genealogía de esta filosofía "ecléctica" nos muestra a Cousin desprendiéndose del movimiento de los "ideólogos". Interesados en negar la filosofía del siglo XVIII, los eclécticos se ocupan sólo de las ciencias particulares y recurren a algunas innovaciones extranjeras. Royer-Collard introduce a Reid y la escuela escocesa de psicología experimental. Cousin recoge esta novedad, aunque al poco tiempo terminará dirigiendo su atención hacia la filosofía alemana y en particular a Hegel. Jouffroy, por su parte, a pesar de haber compartido aquellos inicios, no lo seguirá en este derrotero. Jouffroy se conserva junto a los escoceses. $\mathrm{Al}$ tiempo vuelven a reunirse, y allí nace el eclecticismo. "Es esta negación misma de toda filosofía que M. Cousin y M. Jouffroy transformarán en filosofía, hacia el fin de la restauración, bajo el nombre de eclecticismo" (Leroux, P., Réfutation, p. 65). 
colectiva, el criterio será el consentimiento. En todos los casos se ponen en juego las distintas facultades humanas, la observación, la comparación, el análisis, el razonamiento, la memoria, la inducción, la analogía, la síntesis ${ }^{54}$.

No se trata aquí de una discusión epistemológica, lo que subyace a esta descripción y a esta crítica es la preocupación de Leroux por los efectos prácticos de esta concepción de la filosofía. Si la filosofía es por excelencia el estudio de la vida del hombre, tal como la concibe Leroux, ese estudio no puede partir de una descripción objetiva de los fenómenos que estudia como fenómenos físicos. Tal cosa equivaldría a reducir al hombre a su calidad de ser exclusivamente físico empobreciendo la naturaleza humana que es por definición compuesta. Pero en última instancia esta descripción de los fenómenos, pretendidamente objetiva, pone de manifiesto el interés por justificar el dominio sobre los hombres que está a la base de una posición tal. El hombre considerado sólo como ser físico, y por lo tanto separado de los otros, queda a merced del Estado. El "inmovilismo", aquella otra característica del eclecticismo que mencionamos al comienzo, se liga con esto. Los filósofos eclécticos son ajenos al movimiento del siglo, son ajenos al movimiento de la historia y por lo tanto desconocen el espíritu emancipador del siglo XVIII: "hombres para los que la revolución francesa no era nada más que otro acontecimiento histórico, hombres moldeados en la escuela oficial y reaccionaria del imperio" 55 . Este eclecticismo que se ubica entre la filosofía del siglo XVIII y la escuela teológica, "que trata de elevarse sobre las ruinas y con la sustancia de las religiones y las filosofías viene a desembocar en un miserable sincretismo político y se reduce a esta fórmula: tome una dosis de monarquía y una dosis de democracia, usted tendrá la restauración o el justo medio, y éste será el eclecticismo" 56.

Esta negación de la historia se conjuga con la reducción de la filosofía a reflexión que, en términos de los eclécticos, termina por coincidir con la observación. La falta de espontaneidad, la ausencia de corazón, dice Leroux tomándose de Vauvenarges ${ }^{57}$, inmoviliza la filosofía convirtiéndola en "religión", entendiendo aquí religión en un sentido diverso al usado hasta el

\footnotetext{
54 Véase Ibid, pp. 110-111.

55 Ibid, p. 66.

56 Ibid, p. 69.

57 Véase ibid. pp. 337-338.
} 
momento: como algo estático, sin vida. "Es necesario convenir que Cousin, lo mismo que sus colegas, hace todos los esfuerzos para que la naturaleza de las cosas no cambie" 58 y esto se lo debe, según Leroux, a la lectura que hace de Hegel: "la metafísica alemana, pretendiendo la inmovilidad política, había tomado la delantera" 59 .

El filósofo se separa de la sociedad, la filosofía resulta una actividad autónoma que no concibe su relación con otros ámbitos y necesidades del hombre y en este sentido sus respuestas se conciben definitivas y certeras. No obstante, y he aquí lo que parece ser el meollo del planteo de Leroux, esta filosofía, sin mostrar explícitamente su objetivo, es la legitimación de un régimen de dominación. Lo que hace Cousin al reclamar la objetividad de la filosofía, después de haber postulado que su método es la observación, es justificar un orden en el cual la burguesía, esa clase privilegiada no sólo material sino también "espiritualmente", ocupa el poder y, desde allí, maneja una sociedad dominada por una ley ajena ${ }^{60}$. El poder de Cousin en la Universidad y en la enseñanza pública francesa rebela a Leroux. Cousin ejerce, dice, una "tiranía filosófica exorbitante". Dividir para reinar, es el gran lema al que recurre Leroux en su caracterización del eclecticismo. La burguesía, dice Leroux, "tiende por interés y por sentimiento al sistema del individualismo puro" 61 . La división del conocimiento proclamada en la Universidad, la fragmentación del hombre que implica la negación de otras facultades diferentes a la razón, no son sino modos de anular las

${ }^{58}$ Ibid, p. 84.

${ }^{59}$ Ibid. p. 69. Tal como lo entiende Miguel Abensour, "Leroux critica la conciliación hegeliana, es decir, la presentación de Cristo como Dios hecho hombre que tendería a borrar la dualidad irrebasable de lo divino y de lo humano". Según Abensour, Leroux cuestiona la unidad esencial, presente en el planteo hegeliano, de la naturaleza divina y la naturaleza humana, que se haría efectiva en la encarnación, "haciendo esto, poniendo a la luz la inconmensurable distancia entre lo divino y lo humano, rehabilitando la Revelación, Leroux, al mismo tiempo que quiere encontrar el sentido de lo heterogéneo, denuncia en el pensamiento hegeliano la pregnancia de una filosofía de la identidad que considera que hay identidad de la identidad y la noidentidad" (Abensour, M., "L'affaire Schelling", p. 129).

${ }^{60} \mathrm{Al}$ respecto es importante revisar el interesante análisis que ofrece Rosanvallon en Le moment Guizot.

${ }^{61}$ Leroux, P., Aux philosophes, p. 193. 
posibilidades de una asociación, digamos, extraestatal. El Estado pasa a constituir la única fuente de relación, la ley establece el modo de dicha relación.

Si bien es cierto que estos desarrollos de Leroux se asientan sobre una elaboración metafísica y antropológica de la que, por cuestiones de espacio, no podemos dar cuenta aquí, lo que hemos dicho nos permite comprender en qué sentido es posible, siguiendo las huellas de Abensour, reconocer en las formulaciones de Leroux no sólo la posibilidad de hablar de "filosofía política" en el contexto del pensamiento liberal francés del siglo XIX, sino también analizar el sentido que en ese marco adquiere el recurso a la religión. En el contexto de los debates franceses de esa época, y fundamentalmente del lugar que ocupa la "filosofía oficial" y del poder que recae sobre ésta en el marco de la monarquía de Julio, puede comprenderse esta apelación de Leroux y de algunos de sus contemporáneos a la religión y a su vínculo con la filosofía. Esta nueva filosofía y esta nueva religión antes de ponerse al servicio de regímenes tendientes a la concentración del poder, como sugiere Bénichou, se postulan como herramientas de la democracia.

Siguiendo entonces la sugerencia de Abensour, y reparando en las formulaciones de Leroux, se produce un cambio de signos respecto de la lectura de Bénichou. Aquello que para este último era expresión de un modelo que abogaba por la libertad, el eclecticismo, es visto aquí como una filosofía interesada en limitarla y puesta al servicio de la legitimación de un régimen de concentración del poder y contrario por ello a la democracia. Si en la lectura de Bénichou el recurso a la religión puede ser leído como fuente de futuros "totalitarismos", con Abensour adopta el sentido inverso, y la religión es la principal herramienta de la libertad. Pero tal cosa sólo se comprende cuando hemos advertido que "religión" se dice de muchos modos, igual que "libertad" y "democracia".

Recibido : 09/2010; aceptado : 10/2010. 